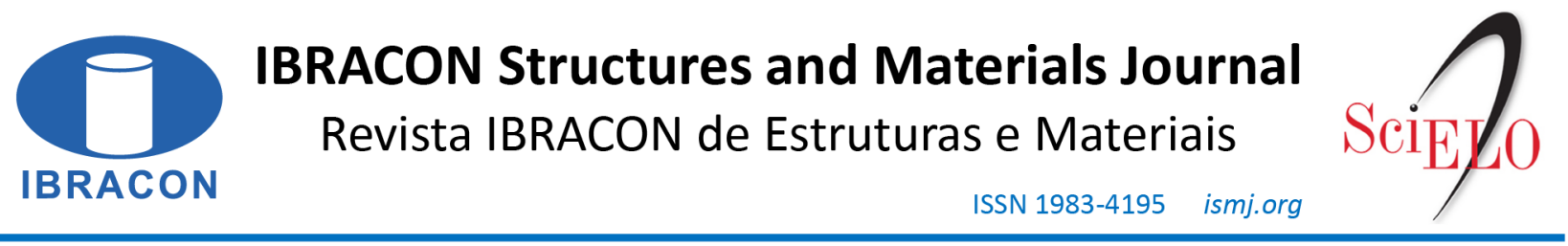

ORIGINAL ARTICLE

\title{
Analysis of constructive effect and soil-structure interaction in tall building projects with shallow foundations on sandy soils
}

\section{Análise do efeito incremental e interação solo-estrutura em edifícios altos com fundações superficiais em solos}

\author{
Olivia Catelan Marques ${ }^{\mathrm{a}}$ \\ Leonardo Almeida Feitosa ${ }^{\mathrm{a}}$ \\ Katia Vanessa Bicalho ${ }^{\mathrm{a}}$ (D) \\ Elcio Cassimiro Alves ${ }^{\mathrm{a}}$ (D)
}

${ }^{a}$ Universidade Federal do Espírito Santo - UFES, Departamento de Engenharia Civil, Vitória, ES, Brasil

Received 01 March 2019

Accepted 20 May 2020

\begin{abstract}
The influence of incremental constructive effects (IE) and soil-structure interaction (SSI) on highrise buildings of reinforced concrete with shallow foundations on sandy soils were analyzed. IE and SSI evaluations were carried out by the parameters of global instability, maximum horizontal displacements, foundation loads, and settlements of a symmetrical and non-symmetrical plant of a 23 -storey building For the analysis of the IE, the variation of the modulus of elasticity was considered over time along with the phases of application of loads in the building. For ISS analysis, the continuous medium was considered, and the calculation model considers a multi-spring-mass system under the foundation of the building. The results show a significant redistribution in the foundation efforts and suggest that a failure in considering these effects along with the structure can lead to projects that do not meet the standard specifications regarding stability parameters and overall structure displacements.
\end{abstract}

Keywords: global stability, constructive effects, soil-structure interaction, shallow foundations, reinforced concrete.

\begin{abstract}
Resumo: Neste artigo analisa-se a influência dos efeitos construtivos incrementais (EI) e da interação solo estrutura (ISE) em edifícios altos de concreto armado com fundações superficiais assentes sobre solos arenosos. Foram realizadas avaliações dos EI e ISE nos parâmetros de instabilidade global, deslocamentos horizontais máximos, cargas de fundação e recalques de uma planta simétrica e uma não simétrica de um edifício com 23pavimentos. Para análise do EI considerou-se a variação do módulo de elasticidade ao longo do tempo, bem como as fases de aplicação de cargas na edificação. Para análise do ISE foi considerado o meio contínuo e o modelo de cálculo considera uma série de molas discretas sob a base da fundação da edificação. Os resultados mostram uma redistribuição significativa nos esforços da fundação e sugerem que a não consideração desses efeitos em conjunto na estrutura pode levar a projetos que não atendam as especificações de norma quanto aos parâmetros de estabilidade e deslocamentos globais da estrutura.
\end{abstract}

Palavras-chave: estabilidade global, efeito incremental, interação solo-estrutura, fundação superficial, concreto armado.

How to cite: O. C. Marques, L. A. Feitosa, K. V. Bicalho, and E. C. Alves, "Analysis of constructive effect and soil-structure interaction in tall building projects with shallow foundations on sandy soils," Rev. IBRACON Estrut. Mater., vol. 14, no. 1, e14103, 2021,

https://doi.org/10.1590/S1983-41952021000100003

\section{INTRODUCTION}

With use of expensive land located in the central area of Brazilian cities, a verticalization is observed with the frequent construction of tall buildings with more than 20 stories high. The analysis of the load redistribution in the 
structure, as well as the structure overall stability evaluation, become important in the building conception, since it ensures the safety of the structure through the loss of its resistant capacity caused by the increase of deformations due to actions on the building.

Generally, the dimensions of the projects are done in a simplified way and do not always represent the physical reality of the work. Thus, important factors that are not normally considered, such as the constructive (or incremental) effect and the soil-building interaction is disregarded in the design.

One of the points that is important to be considered in these analyses are the efforts produced during the construction process, since most shipments happen even before the structure is complete. The Incremental Constructive Effect, called in this work Incremental Effect (IE) contemplates the consideration of these steps in the calculation process. Studies such as Prado [1] and Gorza [2] consider this analysis.

Another relevant point is an integrated analysis of the three parts that constitutes the edifications: superstructure, infrastructure and foundation ground, on a mechanism called Soil-Structure Interaction (SSI) where the rigidity of the whole building is considered in its analysis of stability, loads and pressurized system.

The study of the effect of SSI can be observed for different types of projects and load states. Ge et al. [3], Saragi et al. [4], Galvín et al. [5] present in their studies the importance of soil-structure interaction considering effects of dynamic loads at different scales.

Damgaard et al. [6], Lombardi et al. [7], Bhattacharya et al. [8] present various analyses for different types of projects where the importance of considering soil-structure interaction for the structural models studied was pointed out. Su and Wang [9] present a finite element model for a study with equivalent dynamic load considering the soilstructure interaction and Papadopoulos et al. [10] present in their study the determination of the modal characteristics of structures considering the soil-structure interaction.

Ge et al. [11] analyze the soil-structure interaction considering the movement of soil in building projects and the impacts on neighboring buildings.

On the other hand, Alves and Feitosa [12], Danziger et al. [13], Feitosa and Alves [14], Gusmão [15], Savaris et al. [16], Pavan et al. [17], Agrawal and Harne [18] study (SSI) for buildings, but don't consider the influence of the incremental effect on the analyses performed.

In this context, the study is based on the analysis of the overall stability of the building, associated with the redistribution of efforts in the foundations. Consideration of EI and SSI analyses is expected to lead to changes in these parameters.

Previous studies allow us to conclude that the models that consider both analyses will be more unstable when compared to those that disregard. Works such as Marques et al. [19] and Jucá et al. [20] show this variation studied.

The objective of this paper is to evaluate the influence and relevance of incremental effects associated with the soilstructure interaction in buildings with shallow foundations based on sandy soils. The focus is to verify whether using a more refined model can lead to more critical design considerations of the analyses without them.

It is important to evaluate whether this analysis will generate values relevant to the project parameters, such as global instability and effort redistribution. Thus, the cost-benefit analysis of this new form of analysis is especially important.

For this study, two models of reinforced concrete buildings are analyzed, both with shallow foundation, but one model with symmetrical structure and another with asymmetric structure (insertion of balconies). Cad/TQS v19 [21] software that considers the building as a spatial gantry, composed of elements that will simulate beams, pillars and slabs of the structure, is used as an analysis tool. The floors are defined by grid model on the slabs.

\section{INCREMENTAL EFFECT (IE)}

The structural analysis should consider the sequence of applied load history. As the self weight load of a floor is given immediately after its installation, it does not affect the deformation of the upper floors that do not exist yet.

The Incremental Effect (or incremental analysis) is defined as being the consideration of the construction steps influence in a building.

Prado [1] concluded that introducing loads in an incremental form on the structure results in different values from those obtained by usual calculating methods. He emphasizes that it is necessary to consider premature shipments, since they increase deformations and endanger safety.

Gorza and Coelho [22] evaluate the influence of the transversal rigidity to the bending of the slabs and the construction and loading sequence in a building with metallic structure. And they conclude that the consideration of the transversal rigidity of the slab results in a more realistic analysis of each floor, in that way, it is possible to reduce dimensions of structural parts. In incremental analysis, it was possible to prove that its consideration generates different 
values, when it is compared to conventional analysis, of efforts and shifts. In relation to the efforts it was possible to verify the reduction, and in relation to the shifts, the maximum different shifts were found approximately half height of the building and not at the top as normally.

In this work, the analysis model used in IE was based on calculation of the variation of the modulus of elasticity. The axial rigidity of the pillars is increased in the space gantry, considering an analysis closer to physics reality of the behavior of the structure. At each stage of construction (07 days), a portion of the load's acts on the floor, thus creating the stages of construction regarding the shipments, and 01 floor is built at the same time. These data are presented in Table 1.

Table 1 Incremental Effect Load History

\begin{tabular}{|c|c|c|}
\hline Shipments Cases & Portion (\%) & Phase \\
\hline \multirow{2}{*}{ All permanent and accidental pavements } & 0 & 0 \\
\hline & 100 & Final \\
\hline \multirow{2}{*}{ Own weight } & 100 & 0 \\
\hline & 0 & Final \\
\hline \multirow{4}{*}{ Dead loads } & 0 & 0 \\
\hline & 30 & 1 \\
\hline & 60 & 2 \\
\hline & 10 & Final \\
\hline \multirow{4}{*}{ Live loads } & 0 & 0 \\
\hline & 50 & 1 \\
\hline & 15 & 2 \\
\hline & 35 & Final \\
\hline \multirow{2}{*}{ Wind $90^{\circ}$} & 0 & 0 \\
\hline & 100 & Final \\
\hline \multirow{2}{*}{ Wind $270^{\circ}$} & 0 & 0 \\
\hline & 100 & Final \\
\hline \multirow{2}{*}{ Wind $0^{\circ}$} & 0 & 0 \\
\hline & 100 & Final \\
\hline \multirow{2}{*}{ Wind $180^{\circ}$} & 0 & 0 \\
\hline & 100 & Final \\
\hline \multirow{2}{*}{ Wind $45^{\circ}$} & 0 & 0 \\
\hline & 100 & Final \\
\hline \multirow{2}{*}{ Wind $135^{\circ}$} & 0 & 0 \\
\hline & 100 & Final \\
\hline \multirow{2}{*}{ Wind $225^{\circ}$} & 0 & 0 \\
\hline & 100 & Final \\
\hline \multirow{2}{*}{ Wind $315^{\circ}$} & 0 & 0 \\
\hline & 100 & Final \\
\hline
\end{tabular}

\section{SOIL-STRUCTURE INTERACTION (SSI)}

A building is divided into three parts, superstructure, infrastructure and foundation ground, integrated by the mechanism called soil-structure interaction. However, in practice, this factor is usually not analyzed, and may generate results that do not match the reality of the structure in the service boundary state.

The soil-structure interaction is defined by the consideration of the parts working together. That is, the building is considered in a complete and unified way. In the CAD/TQS model [21], the program generates a stiffness matrix based on the characteristics of the modeled soil, and thus calculates the deformations in the foundation. With this data, the software returns to the spatial portico a model of springs that will be used in the calculation of the additional efforts generated in the building due to soil deformation.

According to ABNT NBR 6118 [23], soil-structure interaction should only be considered in more complex cases of structural analysis. Apart from this orientation, the standard does not contemplate the subject, leaving it up to the designer to choose or not to use the method of analysis.

Albuquerque and Gusmão [24] studied the soil-structure interaction for building in reinforced concrete with shallow foundation. The researchers show that for most buildings with monitoring, the estimated displacements are greater than those measured. This is due to the standardization of the settlements and a redistribution of the loads of the pillars, where the most loaded tend to settle less than expected and the less, more than expected. 
Alves and Feitosa [12], concluded that the consideration of the soil-structure interaction leaves the structure more flexible, increasing the parameter $\gamma_{z}$ (parameter of instability defined by ABNT NBR 6118 [23] that represents the stability of the structure for the analysis of 2 nd order efforts) The analysis of global stability considering soil-structure interaction showed that this influence should be taken into account in daily life, such importance. The results were for symmetrical buildings in reinforced concrete formed by flat slabs and rigid cores, modeled on Cad/TQS software [21].

In their comparison of a real building with a numerical simulation, Savaris et al. [16] verify the importance of joint consideration of structure and foundations. The simulation was able to prove the redistribution of the loads, and the settlements monitoring equipment was effective in its verification. In addition, the results of the analysis proved that the effects of SSI are more significant for calculations on the first floors.

Danziger et al. [13], confirm that loads are redistributed to the peripheral pillars when considering SSI, relieving the central pillars for an analysis of symmetrical buildings with shallow foundation, in reinforced concrete.

Souza and Reis [25] found that the consideration of SSI introduced differences for the efforts working on the pillars, always presenting average values greater than $20 \%$ in relation to the model that disregards. The researchers mention that the consideration of SSI can be of great importance in cases that have great normal strength concentrated in certain pillars or in shoes seated on stratified soils. The analysis of the models proved that CAD/TQS software represents a very effective tool, providing a more realistic analysis than that usually practiced (without SSI), in symmetrical models in reinforced concrete.

Passos et al. [26] concluded that the use of SSI should be done by the structural calculation offices, since it increases the value of the parameter $\gamma_{\mathrm{z}}$. The analysis was based on a study of a symmetrical building with deep foundation in reinforced concrete, with the aid of CAD/TQS software [21].

Pavan et al. [17] proved that the soil-structure interaction generates variations in the active efforts. And, they mention that disregarding the influence of support displacements can lead to unrealistic efforts, which can impair the safety and durability of buildings. These conclusions commend buildings built of symmetrical reinforced concrete and with shallow foundations.

Rosa et al. [27] performed an analysis of the soil-structure interaction focused on creep and retraction, where they compared a real building with a modeling in Sap2000 software. The non-symmetrical construction, in reinforced concrete, with mixed foundation, presented calculated results consistent with those measured in the field. They conclude that the consideration of fluency and retraction in numerical analysis indicates for an evaluation more than its real significance when compared only to the effect of the interaction.

In this work, the calculation of the soil-structure interaction considers the unset foundation and quantifies the effect of the deformability of the foundation soil considering the continuous medium. The calculation model is represented by a multi-spring-mass system under the foundation base. The vertical settlement coefficient is estimated based on the results of the in-situ standard penetration tests (SPT), whose geotechnical profile is shown in Figure 1.

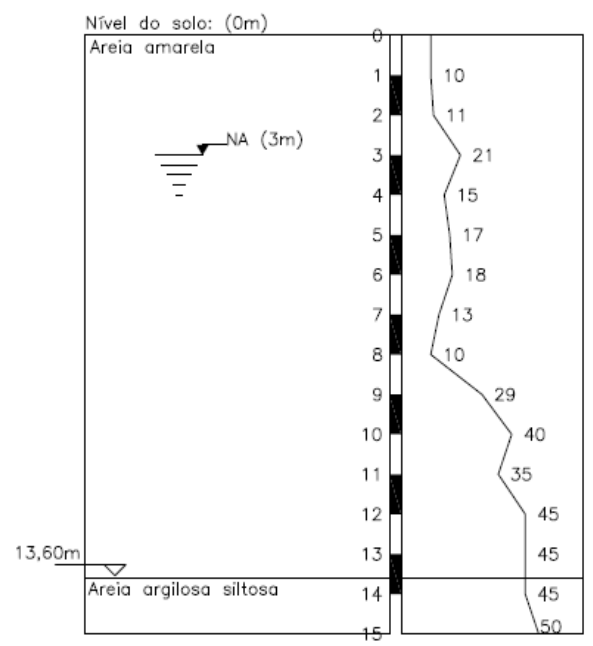

Figure 1 Geotechnical profile with subsurface SPT survey results

The model for analysis of the settlement of shallow footings on sandy soil was proposed by Schmertmann et al. [28], who uses the calculation of the modulus of elasticity estimated by the in-situ tests results. The vertical reaction coefficient represents the resistance of the soil in relation to an imposed displacement, analogous to a spring coefficient. 


\section{INCREMENTAL EFFECT X SOIL-STRUCTURE INTERACTION}

In building projects, usually the analysis of incremental effects, as well as soil-structure interaction is not routine, in view of the difficulties to understand these models. Models involving the analysis of the two parameters together, makes the analysis of the building somewhat more sophisticated and with a higher computational cost, so that few studies are found for this project model.

Jucá et al. [20] compared models considering or not the soil-structure interaction, and evaluated the settlement of footings on sands. The results showed that the model that disregards the soil-structure interaction overestimates the prediction of differential settlements, since it does not consider the stiffness of the structure. The model that considers SSI, but applies instant loading to the complete structure, without the incremental effect, ended up underestimating the prediction of footing settlements. This was due to the non-consideration of the gradual loading in the structure and the increase in stiffness, which leads to the consideration of a greater stiffness than the actual one. The closest result to that found in the field was the one in which the soil-structure interaction was considered associated with the incremental effect.

Albuquerque and Gusmão [24] show that the constructive sequence has greater importance in the first floors, increasing the stiffness in them.

Marques et al. [19] suggest that the use of CAD/TQS software [21] considering SSI showed relevant values in global stability: there was an increase in all wind models analyzed. For the incremental effect, they did not observe any change in the resulted values, when compared with the simple model of the software. The conclusion was based on a study of a building in symmetrical reinforced concrete, with shallow foundations as footings.

\section{METHODOLOGY}

For the combined analysis of the incremental effect (IE) and the soil-structure interaction (SSI) on the global stability, 4 models were analyzed considering the same symmetrical building and 4 models considering non symmetric building were analyzed, with the models $1.1-1.4$ and 2.1-2.4 respectively.

The starting point for the analysis of the models of each group was the development of a model that presented the value of the parameter of instability $\gamma_{\mathrm{z}}$ as close as possible to the limit value indicated by ABNT NBR 6118 [23], which is 1.3. The calculation of the instability parameter was performed by the P-Delta simplified method.

To point out the influence of IE and SSI, models 1.1 and 2.1 were defined as reference models. Models 1.2 and 2.2 used the IE analysis only. On the other hand, in models 1.3 and 2.3, the SSI analysis was applied. Finally, models 1.4 and 2.4 are those that use both IE and SSI analyses.

The reinforced concrete building with shallow foundations on sandy soils considered in analysis has 23 floors: Ground floor, Garage, Type (20 floors) and Penthouse, with the ceiling height of 4.14 meters. The characteristics of the structural elements considered in the analyzed models are presented in Table 2 and loads in Table 3.

Table 2 Characteristics of structural elements considered in the models analyzed

\begin{tabular}{cccc}
\hline Beams: & 30 & $\mathrm{MPa}$ & $\mathrm{MPa}$ \\
\hline Slabs: & 30 & $\mathrm{MPa}$ & \\
\hline Columns: & 40 & $\mathrm{MPa}$ & $\mathrm{m} / \mathrm{s}$ \\
\hline Foundation & 40 & \\
\hline Wind & 30 & \\
\hline Terrain topographic factor & 1 & \\
\hline Roughness Category & $\mathrm{IV}$ & \\
\hline Height Relation & $\mathrm{h} / 4$ & \\
\hline
\end{tabular}

Table 3 Loads distributed by area in the building considered in the analysis

\begin{tabular}{ccc}
\hline FLOOR & PERMANENT & ACCIDENTAL \\
\hline- & $\mathbf{k N} / \mathbf{m}^{\mathbf{2}}$ & $\mathbf{k N} / \mathbf{m}^{\mathbf{2}}$ \\
\hline Type & 1.0 & 1.5 \\
\hline Garage & 1.0 & 3.0 \\
\hline Common area & 1.0 & 3.0 \\
\hline
\end{tabular}

For the considered models, the criteria of the physical nonlinearity coefficient remained the same, with 0.8 for columns, 0.3 for slabs and 0.4 for beams. In addition, the buildings have $\mathrm{H} / 4$ ratio. 
Figure 2 shows the plan used for symmetrical models 1, as well as the 3D building representation of the modeling. Figure 3 shows the plan and the 3D view for non-symmetrical models. Garage and Ground floor have beam elements that vary the beam dimensions from $25 \times 25 \mathrm{~cm}$ to $30 \times 60 \mathrm{~cm}$; the slabs ranged from 15 to $20 \mathrm{~cm}$ in thickness; the pillars were dimensioned with $25 \times 25 \mathrm{~cm}$ for the areas not related to the projection of the type, the others followed the dimensions related to this one.
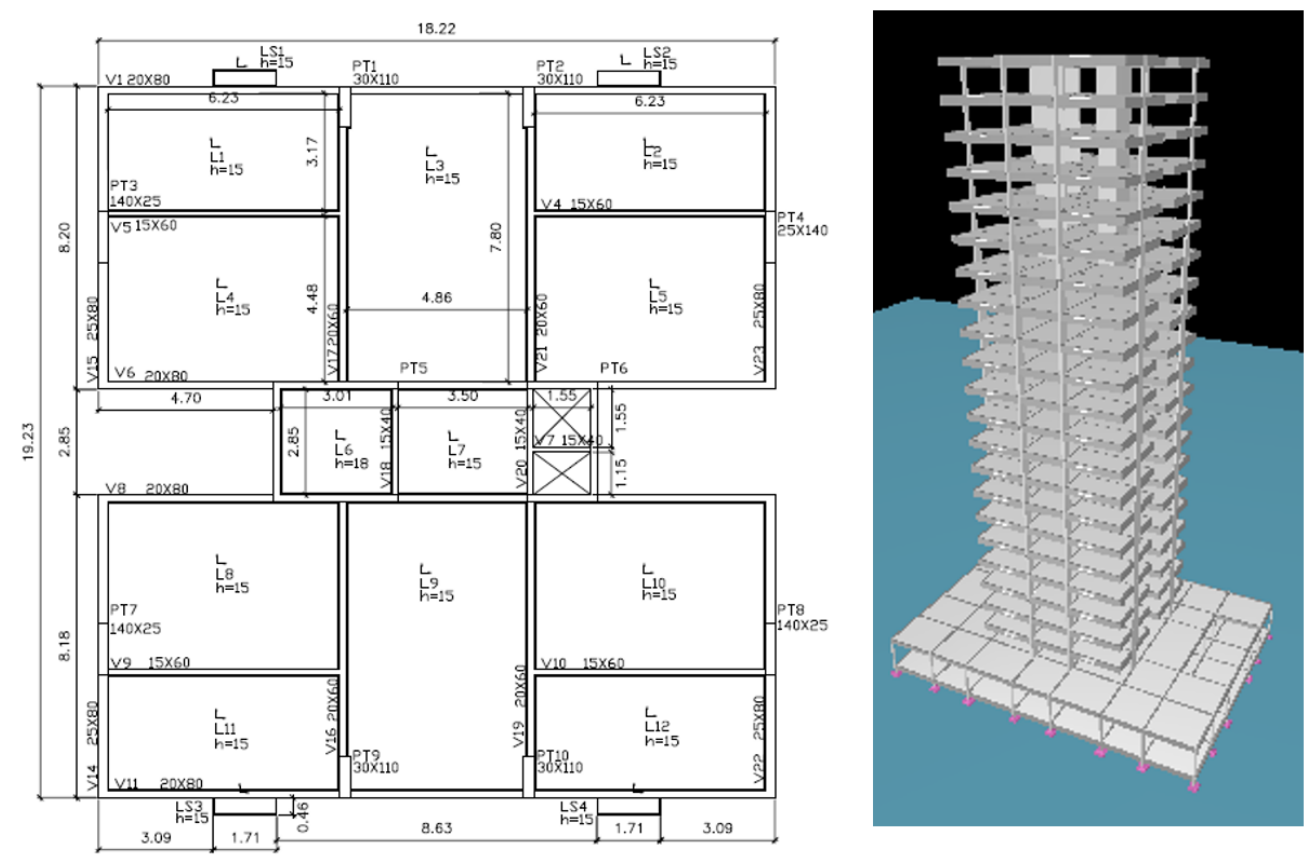

Figure 2 Structural launch layout and 3D view, symmetrical models
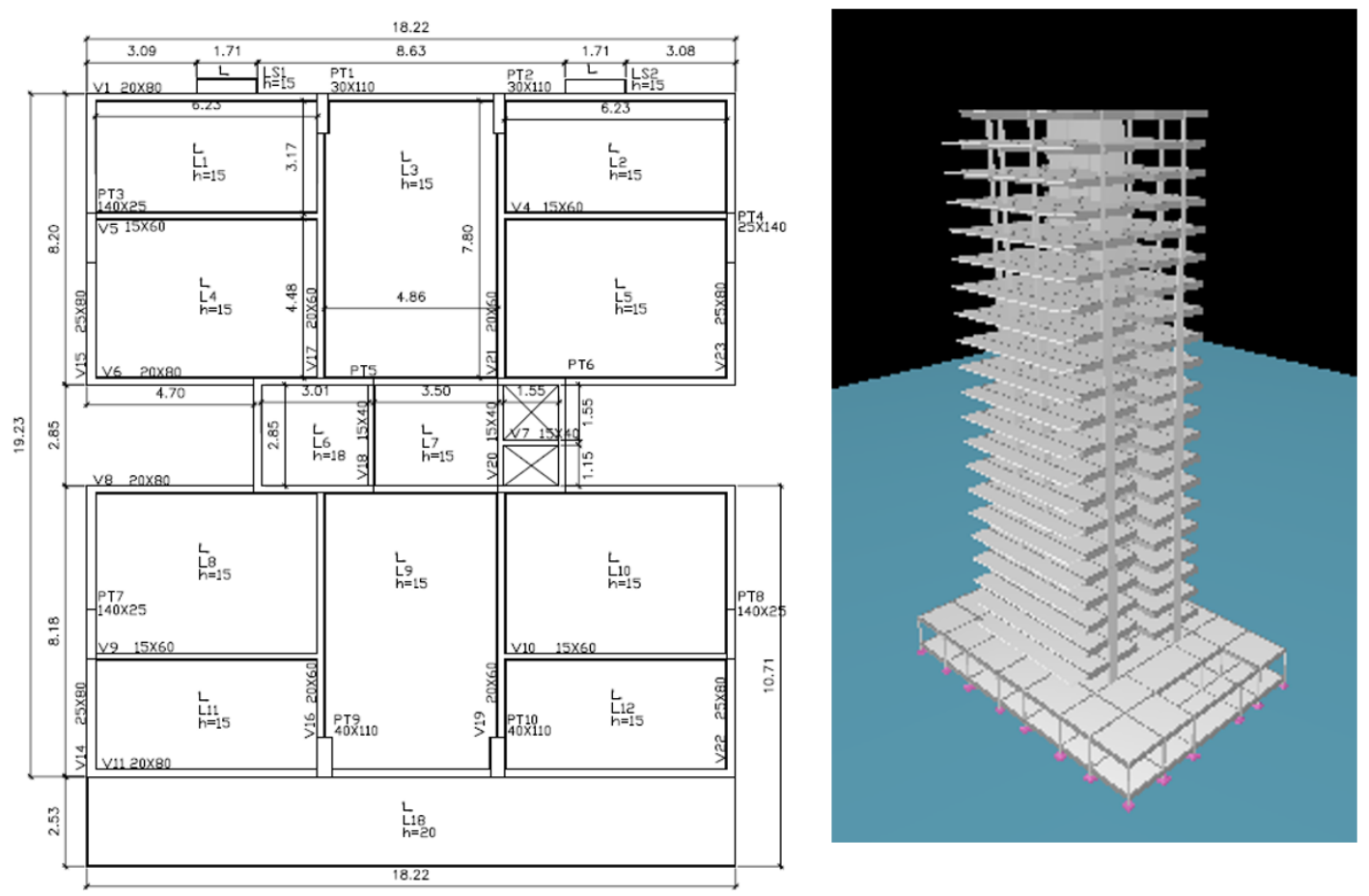

Figure 3 Structural launch layout and 3D view, non-symmetrical models 
Foundation loads and settlements were evaluated according to the combination provided by the software that considers the own limit weight, permanent loads and reduced accidental loads, of the Ultimate Limit State (ULS), for columns and foundation.

\section{RESULTS AND DISCUSSIONS}

\subsection{Instability parameters and maximum horizontal displacements}

In relation to the parameter $\gamma_{\mathrm{z}}$ and maximum horizontal displacements, the results of the first group are presented in Table 4 . The use of the IE generated change in the parameter, even in small values in some cases (Wind $90^{\circ}$ and $270^{\circ}$ ). All cases which SSI was used exceeded the standard limit of 1.3 , which did not happen when the analysis was not considered. The most altered model was the one that considered the analysis with both parameters simultaneously (models 1.4 and 2.4).

Table 4 Instability parameters $\gamma_{\mathrm{z}}$ and maximum horizontal displacements

\begin{tabular}{|c|c|c|c|c|c|}
\hline \multirow{3}{*}{ MODEL } & & \multicolumn{2}{|c|}{$\gamma_{z}$} & \multicolumn{2}{|c|}{$\begin{array}{c}\text { HORIZONTAL } \\
\text { DISPLACEMENTS }\end{array}$} \\
\hline & & \multicolumn{4}{|c|}{ Wind } \\
\hline & & $90^{\circ}-270^{\circ}$ & $0^{\circ}-180^{\circ}$ & $90^{\circ}-270^{\circ}$ & $0^{\circ}-180^{\circ}$ \\
\hline \multirow{4}{*}{ SYMMETRICAL } & 1.1 & 1.150 & 1.090 & 1.65 & 1.00 \\
\hline & 1.2 & 1.151 & 1.090 & 1.66 & 1.00 \\
\hline & 1.3 & 1.305 & 1.306 & 2.72 & 2.74 \\
\hline & 1.4 & 1.311 & 1.306 & 2.61 & 2.85 \\
\hline \multirow{4}{*}{ NON-SYMMETRICAL } & 2.1 & 1.162 & 1.098 & 1.62 & 1.36 \\
\hline & 2.2 & 1.162 & 1.098 & 1.63 & 1.38 \\
\hline & 2.3 & 1.323 & 1.314 & 2.64 & 3.11 \\
\hline & 2.4 & 1.327 & 1.315 & 2.53 & 3.23 \\
\hline
\end{tabular}

For the symmetrical models the maximum changes occurred in the SSI models for $0^{\circ}$ and $180^{\circ}$ Wind cases, with a $19.82 \%$ increase. Model 1.2 showed a minimum difference of $0.09 \%$ compared to 1.1 , so there was no considerable percentage increase. Although the model with SSI and IE showed change in value, it was not relevant in comparative values. Similarly, for the non-symmetric models the largest changes occurred in the SSI models for $0^{\circ}$ and $180^{\circ}$ Wind cases, with a $19.76 \%$ increase. Model 2.2 showed no difference when compared to 2.1, so there was no percentage increase. All models with SSI varied between 10 and $20 \%$. Comparatively, both groups of models showed similar results.

For maximum horizontal displacements, the models with IE (1.2 and 2.2) show smaller changes when compared to the base models. Those using SSI had the greatest values.

ABNT NBR 6118 [23], according to table 13.3, determines that the maximum displacement is:

$\operatorname{Des} l H=\frac{H}{1700}$

Where: DeslH -- Maximum displacement allowed by norm; H - Total height of the building.

For the studied cases, all the values found are in the limit proposed by the $40.2 \mathrm{~mm}$ norm, even those models that present $\gamma_{\mathrm{z}}$ beyond the norm.

Symmetrical models that used SSI more than doubled the value, for the most part. The addition to using IE was only negligible. The largest variations were for $0^{\circ}$ and $180^{\circ}$ Wind cases in model 1.4 , with a $185 \%$ increase compared to the base model. For the non-symmetrical models, model 2.2 presents alteration when compared to 2.1, for two Wind cases, but variations less than $1 \%$. Models 2.3 and 2.4, which use SSI, had the greatest values, with a maximum displacement of $4.30 \mathrm{~cm}$, that means in some cases displacements were greater than the value imposed by the standard. Model 2.4 presented the greatest values of all wind cases.

The introduction of an asymmetry in the building made the maximum horizontal displacements a little more sensitive to IS and SSI. All wind cases generated greater changes than $90^{\circ}$ and $270^{\circ}$ cases. For the most critical situation 
there was a $38 \%$ increase from the asymmetric structure to the symmetrical structure for $0^{\circ}$ and $180^{\circ}$ wind cases in models 2.1 and 2.2 .

Symmetric models that used SSI more than doubled the value, mostly. The addition to using IE was only negligible. The greatest variations were for $0^{\circ}$ and $180^{\circ}$ Wind cases in model 1.4 , with a $185 \%$ increase compared to 1.1 . Nonsymmetrical models that used SSI more than doubled the value for some Wind cases. The maximum variation occurred for $0^{\circ}$ and $180^{\circ}$ Wind cases and was $134.06 \%$.

\subsection{Loads and settlements of shallow foundations on sand}

The shallow foundations (i.e., footings) were identified in: central, peripheral and garage. This separation facilitates understanding of loads distribution. Figure 4 shows a schematic that represents how this classification was made. In this model, the central shallow foundation was characterized as the footing foundation 20 , the peripheral one related to the main building $(11,12,13,23,24,29)$ and the others as garage. This separation facilitates the understanding of loads distribution.

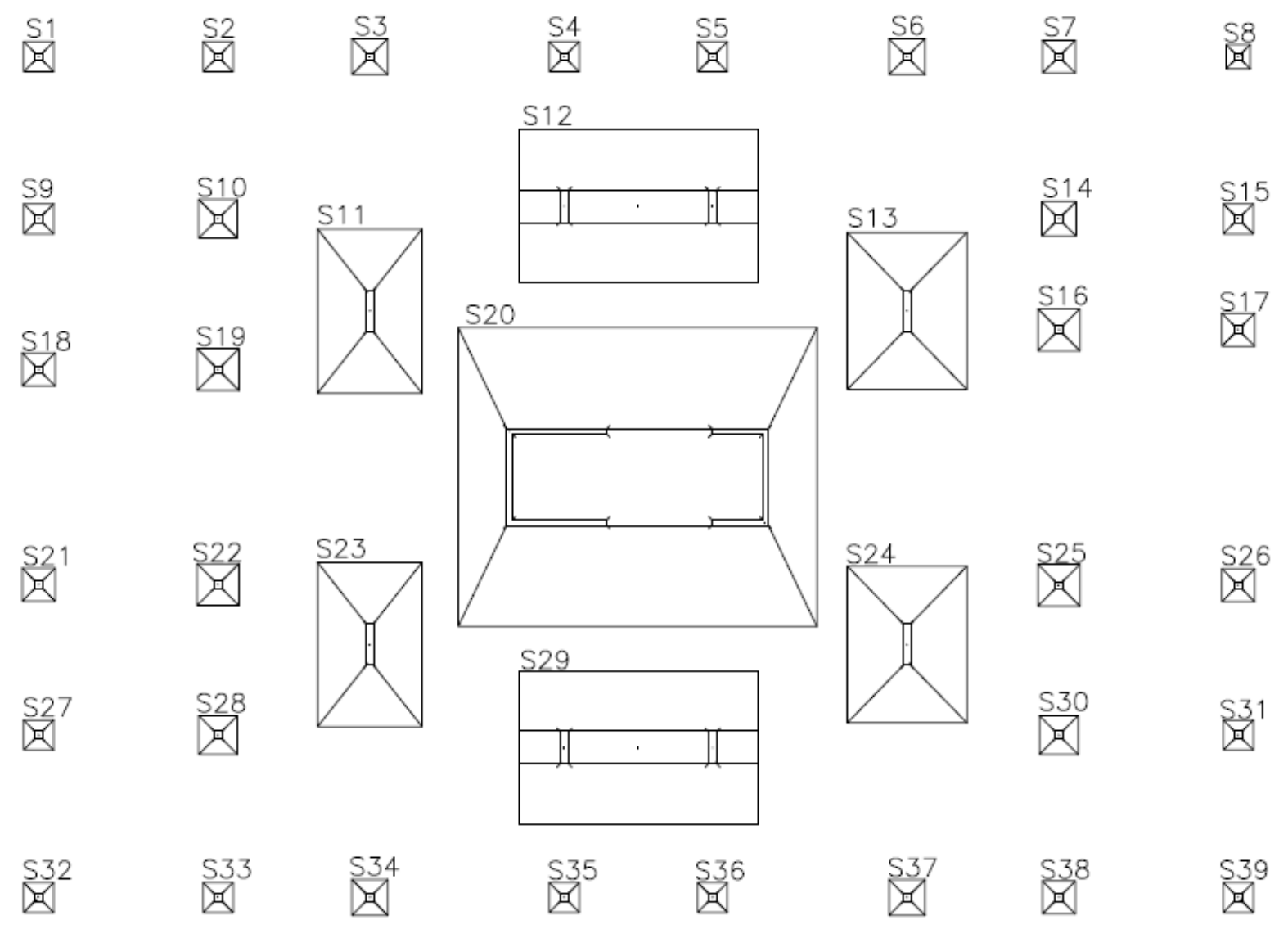

Figure 4 Structural launch of the shallow foundation

The results of the foundation load analysis are presented in Table 5. For both symmetrical and non-symmetrical models, the garage shallow foundation showed slight changes when compared to the model with IE as a base. All the peripheral shallow foundation of 1.2 and 2.2 suffered a decrease in loading, and the central one increased. For the use of SSI, models 1.3 and 2.3, in relation to effort redistribution, when compared to the base models, the garage shallow foundation have undergone more relevant changes. The peripheral ones suffered different variations, with 12 and 29 with decrease of the loads and the others with increase; the central shoe had a decrease in load. The most relevant variations were in the garage shallow foundation. The use of IS in conjunction with SSI, model 1.4 and 2.4 showed a smaller redistribution when compared to 1.3 and 2.3 respectively, that means, the model showed smaller differences in the periphery and larger shallow foundation in the central shoe, but following the model logic with only SSI for the most part. 
Table 5 Loads in the foundation in the building considered in the analysis $(\mathrm{kN})$

\begin{tabular}{|c|c|c|c|c|c|c|c|c|c|}
\hline \multirow{2}{*}{$\begin{array}{l}\text { SHALLOW } \\
\text { FOUNDATION } \\
\text { POSITION }\end{array}$} & \multirow{2}{*}{$\begin{array}{c}\text { SHALLOW } \\
\text { FOUNDATION }\end{array}$} & \multicolumn{4}{|c|}{ SYMMETRICAL } & \multicolumn{4}{|c|}{ NON-SYMMETRICAL } \\
\hline & & 1.1 & 1.2 & 1.3 & 1.4 & 2.1 & 2.2 & 2.3 & 2.4 \\
\hline \multirow{32}{*}{ GARAGE } & 1 & 113 & 113 & 118 & 116 & 113 & 113 & 117 & 115 \\
\hline & 2 & 235 & 235 & 237 & 237 & 235 & 235 & 236 & 235 \\
\hline & 3 & 284 & 285 & 308 & 310 & 284 & 284 & 305 & 307 \\
\hline & 4 & 186 & 190 & 300 & 306 & 185 & 189 & 291 & 297 \\
\hline & 5 & 186 & 191 & 299 & 305 & 186 & 190 & 290 & 296 \\
\hline & 6 & 280 & 280 & 301 & 303 & 280 & 280 & 298 & 301 \\
\hline & 7 & 248 & 248 & 251 & 251 & 247 & 248 & 250 & 249 \\
\hline & 8 & 121 & 121 & 120 & 120 & 121 & 121 & 119 & 118 \\
\hline & 9 & 225 & 224 & 206 & 306 & 225 & 225 & 208 & 207 \\
\hline & 10 & 550 & 552 & 589 & 590 & 550 & 551 & 586 & 587 \\
\hline & 14 & 405 & 406 & 429 & 428 & 405 & 406 & 426 & 426 \\
\hline & 15 & 162 & 161 & 149 & 148 & 162 & 161 & 150 & 148 \\
\hline & 16 & 431 & 435 & 505 & 502 & 431 & 435 & 508 & 506 \\
\hline & 17 & 185 & 185 & 173 & 175 & 185 & 185 & 174 & 175 \\
\hline & 18 & 262 & 260 & 239 & 238 & 262 & 260 & 239 & 238 \\
\hline & 19 & 602 & 606 & 688 & 686 & 602 & 607 & 691 & 690 \\
\hline & 21 & 266 & 265 & 242 & 242 & 266 & 265 & 238 & 238 \\
\hline & 22 & 611 & 616 & 698 & 693 & 611 & 617 & 711 & 706 \\
\hline & 25 & 562 & 567 & 628 & 625 & 562 & 568 & 639 & 637 \\
\hline & 26 & 231 & 230 & 216 & 216 & 231 & 230 & 212 & 212 \\
\hline & 27 & 225 & 224 & 206 & 206 & 225 & 224 & 201 & 202 \\
\hline & 28 & 545 & 547 & 590 & 587 & 544 & 548 & 600 & 595 \\
\hline & 30 & 548 & 550 & 578 & 575 & 548 & 551 & 587 & 583 \\
\hline & 31 & 228 & 227 & 207 & 207 & 228 & 226 & 202 & 202 \\
\hline & 32 & 116 & 116 & 121 & 119 & 116 & 116 & 122 & 121 \\
\hline & 33 & 241 & 241 & 242 & 242 & 241 & 241 & 243 & 243 \\
\hline & 34 & 288 & 289 & 316 & 314 & 288 & 289 & 328 & 327 \\
\hline & 35 & 192 & 198 & 321 & 316 & 194 & 200 & 366 & 364 \\
\hline & 36 & 183 & 198 & 319 & 315 & 194 & 201 & 365 & 365 \\
\hline & 37 & 283 & 284 & 306 & 306 & 284 & 284 & 318 & 318 \\
\hline & 38 & 240 & 241 & 246 & 246 & 241 & 241 & 247 & 246 \\
\hline & 39 & 116 & 116 & 121 & 120 & 116 & 117 & 122 & 121 \\
\hline \multirow{6}{*}{ PERIPHERAL } & 11 & 6707 & 6607 & 6988 & 7079 & 6678 & 6580 & 6845 & 6995 \\
\hline & 12 & 14148 & 13933 & 13727 & 14567 & 13989 & 13805 & 13316 & 14291 \\
\hline & 13 & 6823 & 6765 & 7123 & 7206 & 6796 & 6732 & 6972 & 7109 \\
\hline & 23 & 6937 & 6840 & 7217 & 7013 & 8180 & 7982 & 8488 & 8167 \\
\hline & 24 & 6957 & 6904 & 7324 & 7075 & 8244 & 8100 & 8659 & 8333 \\
\hline & 29 & 15151 & 14897 & 14641 & 14454 & 20651 & 20438 & 19370 & 19439 \\
\hline CENTRAL & 20 & 32375 & 33109 & 31162 & 32059 & 30839 & 31693 & 30698 & 31277 \\
\hline
\end{tabular}

In percentage values, the large variation for model 1.2 happened for the garage footing, with an increase of $8 \%$. The others had minimum variations of $-1 \%$ and the central shallow foundation suffered a load increase of $2 \%$. The model 1.3 obtained more expressive values. The largest variation happens for the same footing as model 1.2, but with maximum values of $74 \%$. Peripheral shallow foundations ranged from $-3 \%$ to $5 \%$ and the center shallow foundation decreased the load value by $4 \%$. In turn, model 1.4 followed the logic of 1.3 , but with smaller values: garage shallow foundations varied by a maximum of $72 \%$, peripherals from $-5 \%$ to $6 \%$ and central $-1 \%$.

For non-symmetrical models, the largest variation for model 2.2 was for the garage shallow foundation, with a $4 \%$ increase. The others had minimum variations of $-1 \%$ and the central shallow foundation suffered a load increase of $3 \%$. The model 2.3 obtained more expressive values. The largest variation happens for the same shallow foundation as 2.2 , but with maximum values of $89 \%$. The periphery shallow foundation ranged from $-6 \%$ to $5 \%$, while the central shallow foundation did not vary the load value. Model 2.4 followed the logic of 2.3, but with smaller values: garage shallow 
foundations varied by a maximum of $88 \%$, peripherals from $-6 \%$ to $5 \%$, and central $1 \%$. Unlike the symmetrical model, shallow foundations 3, 4, 34 and 35 did not show coherence in the variation of values. Shallow foundations 34 and 35 showed larger changes due to the asymmetry of the building.

The analysis of settlements was performed only in the models that used SSI, since the others consider the supports set. Therefore, Table 6 shows the settlement results for models 1.3, 1.4, 2.3, and 2.4.

Table 6 Settlements in the building considered in the analysis $(\mathrm{cm})$

\begin{tabular}{|c|c|c|c|c|c|}
\hline \multirow{2}{*}{$\begin{array}{c}\text { SHALLOW } \\
\text { FOUNDATION } \\
\text { POSITIONS }\end{array}$} & \multirow{2}{*}{$\begin{array}{c}\text { SHALLOW } \\
\text { FOUNDATION }\end{array}$} & \multicolumn{2}{|c|}{ SYMMETRICAL } & \multicolumn{2}{|c|}{ NON-SYMMETRICAL } \\
\hline & & 1.3 & 1.4 & $2, .3$ & 2.4 \\
\hline \multirow{32}{*}{ GARAGE } & 1 & 0.17 & 0.17 & 0.17 & 0.17 \\
\hline & 2 & 0.32 & 0.32 & 0.32 & 0.32 \\
\hline & 3 & 0.36 & 0.36 & 0.35 & 0.36 \\
\hline & 4 & 0.43 & 0.45 & 0.42 & 0.43 \\
\hline & 5 & 0.43 & 0.44 & 0.41 & 0.43 \\
\hline & 6 & 0.35 & 0.35 & 0.34 & 0.35 \\
\hline & 7 & 0.29 & 0.31 & 0.31 & 0.31 \\
\hline & 8 & 0.2 & 0.2 & 0.2 & 0.2 \\
\hline & 9 & 0.27 & 0.27 & 0.27 & 0.27 \\
\hline & 10 & 0.62 & 0.62 & 0.61 & 0.61 \\
\hline & 14 & 0.51 & 0.51 & 0.5 & 0.51 \\
\hline & 15 & 0.2 & 0.2 & 0.21 & 0.2 \\
\hline & 16 & 0.51 & 0.51 & 0.51 & 0.51 \\
\hline & 17 & 0.22 & 0.22 & 0.22 & 0.22 \\
\hline & 18 & 0.29 & 0.29 & 0.29 & 0.29 \\
\hline & 19 & 0.68 & 0.68 & 0.68 & 0.68 \\
\hline & 21 & 0.29 & 0.29 & 0.29 & 0.29 \\
\hline & 22 & 0.68 & 0.69 & 0.7 & 0.7 \\
\hline & 25 & 0.62 & 0.62 & 0.63 & 0.63 \\
\hline & 26 & 0.27 & 0.27 & 0.26 & 0.26 \\
\hline & 27 & 0.27 & 0.27 & 0.27 & 0.27 \\
\hline & 28 & 0.62 & 0.62 & 0.63 & 0.62 \\
\hline & 30 & 0.6 & 0.6 & 0.61 & 0.61 \\
\hline & 31 & 0.27 & 0.27 & 0.27 & 0.27 \\
\hline & 32 & 0.17 & 0.17 & 0.17 & 0.17 \\
\hline & 33 & 0.32 & 0.32 & 0.33 & 0.33 \\
\hline & 34 & 0.37 & 0.37 & 0.38 & 0.38 \\
\hline & 35 & 0.46 & 0.46 & 0.53 & 0.53 \\
\hline & 36 & 0.46 & 0.46 & 0.52 & 0.53 \\
\hline & 37 & 0.36 & 0.36 & 0.37 & 0.37 \\
\hline & 38 & 0.31 & 0.31 & 0.31 & 0.31 \\
\hline & 39 & 0.17 & 0.17 & 0.17 & 0.17 \\
\hline \multirow{6}{*}{ PERIPHERAL } & 11 & 2.24 & 2.28 & 2.2 & 2.24 \\
\hline & 12 & 2.46 & 2.58 & 2.38 & 2.5 \\
\hline & 13 & 2.08 & 2.11 & 2.03 & 2.07 \\
\hline & 23 & 2.31 & 2.26 & 2.59 & 2.51 \\
\hline & 24 & 2.13 & 2.09 & 2.42 & 2.34 \\
\hline & 29 & 2.61 & 2.56 & 3.26 & 3.23 \\
\hline CENTRAL & 20 & 2.7 & 2.77 & 2.54 & 2.63 \\
\hline
\end{tabular}

For all studied models, most values found were similar for garage shallow foundations. All periphery shallow foundations changed their values: footings 11, 12, and 13 increased their displacements with the use of the IE, and footings 23,24 , and 29 decreased, as did the center footing. 
The greatest settlement found for symmetrical models was in the $2.77 \mathrm{~cm}$ center footing, and for $2.63 \mathrm{~cm}$ nonsymmetrical footings for cases 1.4 and 2.4 , respectively. The periphery footings presented smaller values, but in this order of magnitude. As for the garage, none of them reached $1.00 \mathrm{~cm}$.

In garage footings of symmetrical models, the largest change in percentage value was $6 \%$. The peripheral footings ranged from $-2 \%$ to $5 \%$. For the plant, there was a $3 \%$ change in its value. In the case of non-symmetrical models, the largest change in percentage value was $5 \%$ for the garage, the peripheral footings ranged from $-3 \%$ to $5 \%$, while for the central, there was a change of $3 \%$ in its value.

\section{CONCLUSIONS}

The objective of this paper was to evaluate the influence of Incremental Effect and Soil-Structure Interaction on overall stability analyses of a reinforced concrete structure with shallow foundations on sandy soils. For such, the instability $\gamma_{z}$ parameters were analyzed, in addition to foundation loads, settlements and quantity of materials, to complement the analysis and understand how these parameters can influence the design of the building.

Thus, in general, the use of SSI presented more relevant variations, showing to be the most complex tool and requiring more attention from the designer, which is in agreement with the studies of Alves and Feitosa [12] and Marques et al. [19], which draw attention to the variations found in the parameters analyzed.

For SSI and EI, the models presented: great variation in stability and displacement and an intermediate redistribution of loads, demonstrating that they alter the efforts in which the building is submitted in the calculation process.

The results agree with Jucá et al. [20], since the model that considers SSI and IE (models 1.4 and 2.4) increases the instability of the building when compared to without the IE (models 1.3 and 2.3). In relation to the case without the use of ISE, it is not possible to evaluate it, because it was considered the foundation set. Considering that the study done by the authors was compared to a real building, the agreement of the values found highlights the importance of considering these calculation models in the project.

In summary, it is possible to conclude that the joint use of the Incremental Effect and Soil-Structure Interaction parameters are relevant to the final design of the building, especially when these effects are considered in combination.

\section{ACKNOWLEDGEMENTS}

The authors acknowledge TQS Informática for providing the program in its full version for the development of the work, as well as to PPGEC UFES for their support. At the same time, we acknowledge Profa. Cristina Helena Carneiro from IFES for English translations. The third author thanks CNPq for the research grant called scientific productivity fellowship.

\section{REFERENCES}

[1] J. F. M. A. Prado, "Structures of reinforced concrete buildings subjected to construction actions," Ph.D. dissertation, Univ. Fed. São Carlos, São Carlos, 1999.

[2] L. S. Gorza, "Constructive incremental analysis of multi-story metallic building using the finite element method," M.S. thesis, Univ. Fed. Espírito Santo, Vitória, 2000.

[3] O. Ge, F. Xiong, L. Xie, J. Chen, and M. Yu, "Dynamic interaction of soil - structure cluster," Soil. Dyn. Earthquake Eng., vol. 123, pp. 16-30, 2019.

[4] Y. Saragi, M. Irsyam, and H. Roesyanto, "Nonlinear dynamic soil structure interaction in adjacent basement," IOP Conf. Series Mater. Sci. Eng., 2019.

[5] P. Galvín, A. Romero, and J. Domínguez, "Fully three-dimensional analysis of tall-speed train-track-soil-structure dynamic interaction," J. Sound Vibrat., vol. 329, no. 24, pp. 5147-5163, 2010.

[6] M. Damgaard, L. V. Andersen, and L. B. Ibsen, "Computationally efficient modelling of dynamic soil-structure interaction of offshore wind turbines on gravity footings," Renew. Energy, vol. 68, pp. 289-303, Aug 2014.

[7] D. Lombardi, S. Bhattacharya, and D. M. Wood, "Dynamic soil-structure interaction of monopile supported wind turbines in cohesive soil," Soil. Dyn. Earthquake Eng., vol. 49, no. 16, pp. 165-180, Jun 2013.

[8] S. Bhattacharya et al., "Observed dynamic soil-structure interaction in scale testing of offshore wind turbine foundations," Soil. Dyn. Earthquake Eng., vol. 54, no. 14, pp. 47-60, Nov 2013.

[9] J. Su and Y. Wang, "Equivalent dynamic infinite element for soil-structure interaction," Finite Elem. Anal. Des., vol. 63, pp. 1-7, Jan 2013.

[10] M. Papadopoulos, R. Van Beeumen, S. François, G. Degrande, and G. Lombaert, "Modal characteristics of structures considering dynamic soil-structure interaction effects," Soil. Dyn. Earthquake Eng., vol. 105, pp. 114-118, Feb 2018. 
[11] Q. Ge, F. Xiong, J. Chen, and Z. Yao, "Effects of soil-structure cluster interactions on ground motions," Struct. Des. Tall Spec. Build., vol. 29, no. 1, 2020.

[12] E. C. Alves and L. A. Feitosa, "Analysis of the overall stability of tall buildings on flat slabs considering the soil-structure interaction," Int. J. Struct. Mater., vol. 13, pp. 183-199, Feb 2020.

[13] B. R. Danziger, E. M. L. Carvalho, R. V. Costa, and F. A. B. Danziger, "Study of case work with interaction analysis soil-structure," Civ. Eng. Mag., no. 23, pp. 43-54, 2005.

[14] L. A. Feitosa and E. C. Alves, "Study of global stability of tall buildings with prestressed slabs," Int. J. Struct. Mater., vol. 8, no. 2, pp. 196-224, Apr 2015.

[15] A. D. Gusmão, "Study of soil-structure interaction and its influence on building settlements," M.S. thesis, Univ. Fed. Rio de Janeiro, Rio de Janeiro, 1990.

[16] G. Savaris, P. H. Hallak, and P. C. A. Maia, "Influence of foundation settlements in load redistribution on columns in a monitoring construction - case study," Int. J. Struct. Mater., vol. 3, no. 3, pp. 346-356, 2010.

[17] R. C. Pavan, M. F. Costella, and G. Guarnier, "Soil-structure interaction for frame structures on shallow foundations," Int. J. Struct. Mater., vol. 7, no. 2, pp. 260-285, 2014.

[18] N. S. Agrawal and V. R. Harne, "Analysis of reinforced concrete structure considering the influence of soil structure interaction," Helix, vol. 10, no. 1, pp. 98-104, 2020.

[19] O. C. Marques, E. C. Alves, and L. A. Feitosa, "Analysis of instability parameters considering constructive effect and solo-structure interaction in tall-rise design," in Proced. 60th Brazilian Concr. Congr., Foz do Iguaçu, 2018. (In Portuguese).

[20] J. F. T. Jucá, A. O. C. Fonte, and I. D. S. Pontes Fo., "Building performance founded on an improved sand in Recife, Brazil," in Vertical and Horizontal Deformations of Foundations and Embankments, A. T. Yeung and G. Y. Félio, Eds., New York: ASCE, 1994, pp. 1202-1213.

[21] TQS Informática, Theoretical Manual - Soil-structure Interaction System. São Paulo: TQS Informática Ltda., 2018.

[22] L. S. Gorza and L. H. Coelho, "Constructive incremental analysis of multi-story metal buildings - case study," Eng. Sci. Technol. Mag., vol. 3, no. 17, pp. 33-41, 2000.

[23] Associação Brasileira de Normas Técnicas, Design of Concrete Structures - Procedures, NBR 6118, 2014.

[24] R. C. B. L. Albuquerque and A. D. Gusmão, "Considerations on the relevance of soil-structure interaction in settlements: case of a building in the city of Recife," in 2nd Brazilian Symp. Young Geotech., Nova Friburgo, 2006. (In Portuguese).

[25] R. A. Souza and J. H. C. Reis, "Solo-structure interaction for buildings under shallow foundation," Min. Sci. Technol., vol. 30, no. 2, pp. 161-171, 2008.

[26] V. M. Passos, E. C. Alves, and L. A. Feitosa, "Stability analysis of tall buildings on smooth and ribbed slabs with the effect of soilstructure interaction," in Proced. 58th Brazilian Concr. Congr., Belo Horizonte, 2016.

[27] L. M. P. Rosa, B. R. Danziger, and E. M. L. Carvalho, "Soil-structure interaction analysis considering concrete creep and shrinkage," Int. J. Struct. Mater., vol. 11, no. 3, pp. 564-585, Jun 2018.

[28] J. H. Schmertmann, J. P. Hartman, and P. R. Brown, "Improved strain influence factor diagrams," J. Geotech. Eng. Div., vol. 104, no. 8, pp. 1131-1135, 1978.

Author contributions: OCP: conceptualization, data curation, formal analysis, methodology, writing; LAF: conceptualization, data curation, formal analysis; KVB: conceptualization, writing; ECA: conceptualization, data curation, methodology, supervision, writing.

Editors: Bernardo Horowitz, José Luiz Antunes de Oliveira e Sousa, Guilherme Aris Parsekian. 